\title{
Multi Response Optimization of Friction Stir Lap Welding Process Parameters Using Deng's Similarity Based Method
}

\author{
Dr. P Hema ${ }^{1}, \mathrm{P}_{\text {Yamini priya }}{ }^{2}, \mathrm{M}_{\text {Reddeiah }}{ }^{3}$ \\ ${ }^{1}$ Asst.Professor, Dept of mechanical Engg, S.V.U College of Engineering, Tirupathi. \\ ${ }^{2} M$ Tech (Production Engineering), Student, Dept of mechanical Engg, S.V.U College of Engineering, Tirupathi \\ ${ }^{3}$ Teaching Assistant, Dept of mechanical Engg, S.V.U College of Engineering, Tirupathi
}

\begin{abstract}
This study focuses on the effect of process parameters such as Tool rotational speed, Welding speed and Tool tilt angle in Friction stir Lap welding of dissimilar AA 5083 and AA 6082 alloys. Experiments are designed with three different levels of process parameters using Taguchi orthogonal array. As per DOE, experiments are conducted using Taper threaded cylindrical tool which is made up of with $\mathrm{H} 13$ tool steel, on Aluminium plates of $3 \mathrm{~mm}$ thickness. The Tensile shear test specimens are tested at room temperature in order to analyze the mechanical properties. Vicker's hardness is also conducted to check the hardness of welded zone. Multi response characteristics include hardness, shear strength, elongation percentage and peak load are optimized using a multi criteria decision making approach. The optimum values are found at tool rotational speed of 710 $\mathrm{rpm}$, welding speed of $1.5 \mathrm{~mm} / \mathrm{min}$ and tool tilt angle of 1 degree.
\end{abstract}

Keywords: Lap joint, H13 tool steel, FSLW, Process parameters, Shear tensile test, Hardness test.

\section{INTRODUCTION}

Friction stir welding (FSW) [1] is a solid state joining process and melting/solidification related defects of fusion welding are avoided. Since it was invented in early 1990s [1], FSW has been applied quite widely [2]. Many aspects of FSW have been studied extensively and comprehensively reviewed. The majority of FSW studies have been based on butt joint geometry. Lap joint configuration is also widely used in conventional welding and friction stir lap welding (FSLW) should potentially be applied widely, particularly in automotive and aerospace industries. Fig. 1 illustrates FSLW during which a section of lapping surfaces of the top and bottom plates is stirred and mixed in the stir zone (SZ) thus forming a weld behind the tool.

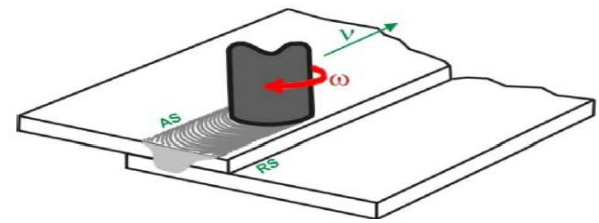

Figure- 1 Friction Stir Lap Welding

From literature gap analysis there is an increasing need to deep research on FSLW. This paper deals with the multi response optimization of FSLW using process parameters such as tool rotational speed, welding speed and tool tilt angle. Experiment was conducted as per Taguchi design and mechanical properties are evaluated by conducting the mechanical tests. Responses are optimized with Deng's similarity based method.

\section{EXPERIMENTAL PROCEDURE}

All FSLW experiments as shown in figure 1 were conducted using Knee type milling machine FN2V. Sheets of aluminium alloy, AA5083 and AA6082 with dimensions $100 \mathrm{~mm}$ long, $150 \mathrm{~mm}$ wide and $3 \mathrm{~mm}$ thick were selected for lap joint welding. Taper threaded cylindrical tool [9] shown in figure 3 used for this process was made up of with H13 tool steel with a shoulder of $18 \mathrm{~mm}$ diameter, pin diameter at the shoulder was $5 \mathrm{~mm}$ and pin diameter at pin end was $4 \mathrm{~mm}$ and pin length was 5 $\mathrm{mm}$. several literature reviews are available for selection of process parameters, namely tool rotational speed, welding speed and tool tilt angle [8]. Three levels of process parameters were selected and L9 orthogonal array was developed using Taguchi method. AA 5083 plate was placed on retreating side of the weld joint and AA 6082 was placed at advancing side. Friction stir lap welding was done on workpieces as per design of experiments.

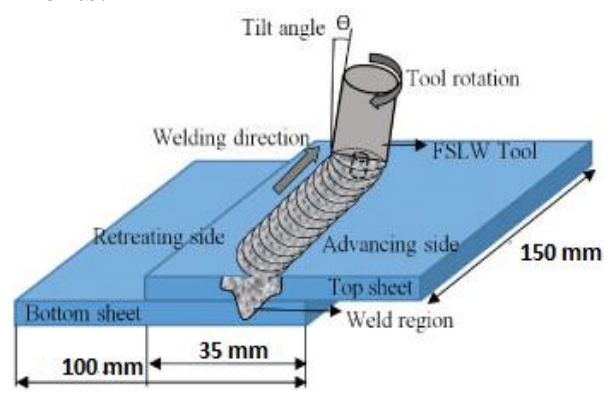

Figure-2 Schematic Figure of FSLW 
Tensile shear testing of lap joint has been the major method used for evaluating strength of welds. Test sample of $35 \mathrm{~mm}$ wide, perpendicular to the welding direction were machined from the welding plates. Specimens were tested using UTM TUE-C-200. The strength of a lap sample cannot be expressed using the normal load/area, as the stress distribution along the joint area during tensile-shear test is highly uneven. Instead, maximum failure load in a test divided by the width of the sample, $F_{m} / w s$, is taken as strength. After conducting the tensile shear test the responses such as shear strength, peak load and elongation percentage were noted.

Vicker's hardness test [8] was used to determine the hardness of the welding zone. Hardness specimen of $25 \mathrm{~mm}$ wide was prepared and specimen was tested using the machine ASTM E38411. Load of 500 gram was applied on the specimen. Hardness is measure at three places of weld zone. Mechanical tests responses are noted in the below table 1 .

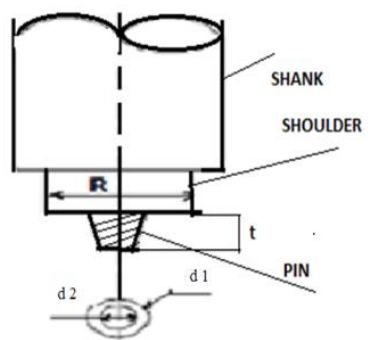

Figure-3 FSLW tool design

\section{DENG'S SIMILARITY BASED METHOD}

Similarity approach presented by (Deng, 2007), makes use of the ideal solution concept in such a way that the most preferred alternative should have the highest degree of similarity to the PIS and the lowest degree of similarity to the NIS. The overall performance index of each alternative across all criteria is determined based on the combination of these two degrees of similarity measure concepts using alternative gradient and magnitude.

Similarity approach presented by (Deng, 2007), makes use of the ideal solution concept in such a way that the most preferred alternative should have the highest degree of similarity to the PIS and the lowest degree of similarity to the NIS. The overall performance index of each alternative across all criteria is determined based on the combination of these two degrees of similarity measure concepts using alternative gradient and magnitude

In this method, the units of all the criteria are eliminated and it has been converted into normalized value. The normalized value $\left(\mathrm{x}_{\mathrm{ij}}\right)$ is obtained using the equation (1)

Step 1: The normalized decision matrix can be found out by determining the normalized value as

$$
\begin{aligned}
& r i j=\frac{x_{i j}}{\sqrt{\sum_{i=1}^{m} x_{i j}^{2}}} \quad \mathrm{i}_{=} 1,2,3 \ldots \ldots \ldots . \mathrm{m}, \\
& \mathrm{j}=1,2,3 \ldots \ldots \mathrm{n} \quad \text { Eq. } 1
\end{aligned}
$$

Where,

$\mathrm{i}=$ Number of alternatives (trials)

$\mathbf{J}=$ Number of criteria (Output responses)

$\mathrm{x}_{\mathrm{ij}}=$ Represents the actual value of the $\mathrm{i}^{\text {th }}$ value of $\mathrm{j}^{\text {th }}$ experimental run.

The normalized matrix is constructed using the above Eq.1 for the table 1 responses Step 2:The weighted normalized decision matrix is constructed by multiplying the normalized decision matrix by its associated weights.

$$
\begin{gathered}
v_{i j}=w_{j} * r_{i j} \quad \text { Eq. } 2 \\
\mathrm{v}_{\mathrm{ij}}=\text { weighted normalized value }
\end{gathered}
$$$$
\mathrm{w}_{\mathrm{j}}=\text { weightage of each responses }
$$

Table 1: Process Parameters and Its Responses

\begin{tabular}{|c|c|c|c|c|c|c|c|}
\hline \multirow{2}{*}{ Exp no } & \multicolumn{2}{|c|}{ PROCESS PARAMETERS } & \multicolumn{4}{|c|}{ RESPONSES } \\
\cline { 2 - 8 } & $\begin{array}{c}\text { Tool } \\
\text { rotational } \\
\text { speed } \\
(\mathrm{rpm})\end{array}$ & $\begin{array}{c}\text { Welding } \\
\text { speed } \\
(\mathrm{mm} / \mathrm{min})\end{array}$ & $\begin{array}{c}\text { Tilt angle } \\
\left({ }^{\circ}\right)\end{array}$ & $\begin{array}{c}\text { Peak } \\
\text { load } \\
(\mathrm{KN})\end{array}$ & $\begin{array}{c}\text { Elongation at } \\
\text { peak } \\
(\mathrm{mm})\end{array}$ & $\begin{array}{c}\text { Shear } \\
\text { strength } \\
\left(\mathrm{N} / \mathrm{mm}^{2}\right)\end{array}$ & $\begin{array}{c}\text { Hardness } \\
(\mathrm{VH} 0.5)\end{array}$ \\
\hline 1 & 710 & 31.5 & 0.5 & 16.09 & 5.84 & 80.04 & 69.9 \\
\hline 2 & 710 & 40 & 1.0 & 15.88 & 5.0 & 76.32 & 70.2 \\
\hline 3 & 710 & 50 & 1.5 & 17.02 & 5.31 & 84.157 & 74.5 \\
\hline 4 & 900 & 31.5 & 1.0 & 7.33 & 3.04 & 35.288 & 72.2 \\
\hline 5 & 900 & 40 & 1.5 & 13.99 & 4.59 & 69.294 & 81.9 \\
\hline 6 & 900 & 50 & 0.5 & 8.46 & 3.32 & 40.647 & 63.9 \\
\hline 7 & 1120 & 31.5 & 1.5 & 4.37 & 2.93 & 22.242 & 58.8 \\
\hline 8 & 1120 & 40 & 0.5 & 5.45 & 1.67 & 26.804 & 69.6 \\
\hline 9 & 1120 & 50 & 1.0 & 15.9 & 4.73 & 76.874 & 73.2 \\
\hline
\end{tabular}


Table 2 Normalized Decision Matrix

\begin{tabular}{|c|c|c|c|c|}
\hline EXP NO & HARDNESS & $\begin{array}{c}\text { SHEAR } \\
\text { STRENGTH }\end{array}$ & $\begin{array}{c}\text { PEAK } \\
\text { LOAD }\end{array}$ & $\begin{array}{c}\text { PERCENTAGE } \\
\text { ELONGATION }\end{array}$ \\
\hline 1 & 0.3294 & 0.4332 & 0.4264 & 0.4583 \\
\hline 2 & 0.3308 & 0.4131 & 0.4209 & 0.3924 \\
\hline 3 & 0.3511 & 0.4555 & 0.4511 & 0.4167 \\
\hline 4 & 0.3403 & 0.1910 & 0.1943 & 0.2386 \\
\hline 5 & 0.3861 & 0.3751 & 0.3708 & 0.3602 \\
\hline 6 & 0.3011 & 0.2200 & 0.2242 & 0.2605 \\
\hline 7 & 0.2771 & 0.1204 & 0.1158 & 0.2299 \\
\hline 8 & 0.3280 & 0.1451 & 0.1444 & 0.1311 \\
\hline 9 & 0.3449 & 0.4161 & 0.4217 & 0.3712 \\
\hline
\end{tabular}

Range standardization was done to transform different scales and units among various criteria into common measurable units in order to compare their weights Range standardization matrix was calculated using Eq. 3.

$X_{i j}^{\prime}=\frac{X_{i j}-\min _{1<j<n} X_{i j}}{\max _{1<j<n} X_{i j}-\min _{1<j<n} X_{i j}}$

where $\max X_{i j}$, min $X_{i j}$ are the maximum and minimum values of the criterion $(j)$ respectively.

The Standard deviation $(S D V)$ is calculated for every criterion by using below equation

$\mathrm{SDV}_{j}=\sqrt{\frac{1}{m} \sum_{i=1}^{m}\left(X_{i j}-\overline{X_{j}}\right)^{2}} \quad$ Eq.4

Where $X_{J}^{\prime}$ is the mean of the values of the $j^{\text {th }}$ criterion after normalization and $j=1,2, . ., n$. After calculating for $S D V$ for all criteria, the next step is to determine the weights, $W_{J}$ of all the criteria considered.

$W_{J}=\frac{S D V_{J}}{\sum_{j=1}^{n} S D V_{j}}$

Eq.5

Table 3 Weights Assign to Criteria

\begin{tabular}{|c|c|c|}
\hline Criteria & SDV & WEIGHT \\
\hline 1 & 0.3358 & 0.1921 \\
\hline 2 & 0.4854 & 0.2776 \\
\hline 3 & 0.4924 & 0.2820 \\
\hline 4 & 0.4339 & 0.2482 \\
\hline
\end{tabular}

From the above table 3 it is found that peak load has maximum weight than other responses. To find the weightage table multiply the weights of each responses with corresponding normalized values in table 2 .

Table4: Weighted Normalized Value

\begin{tabular}{|c|c|c|c|c|}
\hline Exp No & HARDNESS & $\begin{array}{c}\text { SHEAR } \\
\text { STRENGTH }\end{array}$ & $\begin{array}{c}\text { PEAK } \\
\text { LOAD }\end{array}$ & $\begin{array}{c}\text { PERCENTAGE } \\
\text { ELONGATION }\end{array}$ \\
\hline 1 & 0.0633 & 0.1203 & 0.1203 & 0.1138 \\
\hline 2 & 0.0636 & 0.1147 & 0.1187 & 0.0974 \\
\hline 3 & 0.0675 & 0.1265 & 0.1272 & 0.1034 \\
\hline 4 & 0.0654 & 0.0530 & 0.0548 & 0.0592 \\
\hline 5 & 0.0742 & 0.1041 & 0.1046 & 0.0894 \\
\hline 6 & 0.0579 & 0.0611 & 0.0632 & 0.0647 \\
\hline 7 & 0.0532 & 0.0334 & 0.0327 & 0.0571 \\
\hline 8 & 0.0630 & 0.0403 & 0.0407 & 0.0325 \\
\hline 9 & 0.0663 & 0.1155 & 0.1189 & 0.0921 \\
\hline
\end{tabular}

Step 4: The positive ideal solutions and negative ideal solutions are determined as:

Positive ideal solution

$S^{+}=\left\{\left(\operatorname{Max}\left(v_{i j}\right) \backslash j \epsilon J,\left(\operatorname{Min}\left(v_{i j}\right) \backslash j \epsilon J^{\prime}\right) \backslash i=1,2,3 \ldots ..\right\}\right.$

Eq.6

Negative ideal solution

$S^{-}=\left\{\left(\operatorname{Min}\left(v_{i j}\right) \backslash i \epsilon J,\left(\operatorname{Max}\left(v_{i j}\right) \backslash j \epsilon J^{\prime}\right) \backslash i=1,2,3 \ldots ..\right\}\right.$

Eq.7

Where,

$\mathrm{J}$ is a set of beneficial attributes and $\mathrm{J}^{\prime}$ is a set of non-beneficial attributes.

Then the positive ideal solutions and negative ideal solutions are determined using (Eq. 67). As higher hardness, shear strength, peak Load and elongation percentage is desirable so maximum value among the recorded values are considered as positive ideal solution and minimum value is referred as 
negative ideal solution. The positive ideal solution and negative ideal solution are determined and tabulated and shown in Table 5

Step 5

Degree of conflict between each alternative and positive ideal solution and negative ideal solution can calculated as follow

Conflict between the alternative and positive ideal solution can be obtained as $\cos \theta_{i}^{+}=\frac{\sum_{j=1}^{m} y_{i j} y_{j}^{+}}{\sqrt{\sum_{j=1}^{m} y_{i j}^{2}} \sqrt{\sum_{j=1}^{m} y_{j}^{+2}}}$

Eq.8

Conflict between the alternative and negative ideal solution can be obtained as:

$\cos \theta_{i}^{-}=\frac{\sum_{j=1}^{m} y_{i j} y_{j}^{-}}{\sqrt{\sum_{j=1}^{m} y_{i j}^{2}} \sqrt{\sum_{j=1}^{m} y_{j}^{-2}}}$

Table 5 Positive and Negative Ideal Solution

\begin{tabular}{|c|c|c|c|c|}
\hline $\begin{array}{c}\text { Positive Ideal } \\
\text { Solution }\end{array}$ & 0.0742 & 0.1266 & 0.1272 & 0.1138 \\
\hline $\begin{array}{c}\text { Negative Ideal } \\
\text { Solution }\end{array}$ & 0.0532 & 0.0334 & 0.0327 & 0.0325 \\
\hline
\end{tabular}

Step 6: The degree of similarity and conflict between the alternatives and positive and negative ideal solution is calculated as: Degree of conflict:

Degree of similarity

$$
\left|C_{i}\right|=\cos \theta_{i}^{-+} \times\left|A_{i}\right|
$$

$S_{i}^{-+}=\frac{\left|C_{i}\right|}{\left|A^{-+}\right|}=\frac{\cos \theta^{-+} \times\left|A_{i}\right|}{\left|A^{-+}\right|}=\frac{\cos \theta^{-+} \times \sqrt{\left[\sum_{j=1}^{m} y_{i j}^{2}\right.}}{\sqrt{\sum_{j=1}^{m} y_{j}^{-+2}}}$

The below table 6 and 7 were constructed by using the equations 8-10.

Step 7: The overall performance index for each alternative is calculate as:

$P_{i}=\frac{S_{i}^{+}}{S_{i}^{+}+S_{i}^{-}}, i=1,2,3 \ldots$.

Eq.12

Ranking according to Deng's similarity based method

Table 6 Conflict between PIS and NIS and Degree of Conflict

\begin{tabular}{|c|c|c|c|c|}
\hline NO & Cos $\square_{\mathbf{i}}^{+}$ & $\mathbf{C o s} \square_{\mathbf{i}}{ }^{-}$ & ci $^{+}$ & $\mathbf{c i}^{-}$ \\
\hline 1 & 0.05057 & 0.00546 & 0.01083 & 0.001171 \\
\hline 2 & 0.05058 & 0.00551 & 0.010214 & 0.001121 \\
\hline 3 & 0.05057 & 0.00549 & 0.011011 & 0.001196 \\
\hline 4 & 0.04875 & 0.00599 & 0.005683 & 0.00071 \\
\hline 5 & 0.05048 & 0.00571 & 0.009481 & 0.00108 \\
\hline 6 & 0.04994 & 0.00587 & 0.006168 & 0.00073 \\
\hline 7 & 0.04655 & 0.00589 & 0.004235 & 0.00054 \\
\hline 8 & 0.04603 & 0.006062 & 0.004196 & 0.00056 \\
\hline 9 & 0.05054 & 0.005537 & 0.010155 & 0.00112 \\
\hline
\end{tabular}

Table 7 Degree of Similarity, Performance Index and Ranks in Deng's Method

\begin{tabular}{|c|c|c|c|c|}
\hline EXP NO & $\mathbf{S}^{+}$ & $\mathbf{S}^{-}$ & $\mathbf{P}^{+}$ & RANK \\
\hline 1 & 0.04814 & 0.01502 & 0.762233 & 1 \\
\hline 2 & 0.045397 & 0.01427 & 0.760941 & 3 \\
\hline 3 & 0.048946 & 0.01534 & 0.76141 & 2 \\
\hline 4 & 0.025261 & 0.00897 & 0.73799 & 7 \\
\hline 5 & 0.042141 & 0.01376 & 0.753962 & 5 \\
\hline 6 & 0.027416 & 0.00931 & 0.746896 & 6 \\
\hline 7 & 0.018822 & 0.00697 & 0.732475 & 8 \\
\hline 8 & 0.018648 & 0.00718 & 0.724557 & 9 \\
\hline 9 & 0.045133 & 0.01427 & 0.759771 & 4 \\
\hline
\end{tabular}

From the above table 7 , it is clearly visible that run 1 is getting the 1st rank. Hence, the corresponding input parameter i.e. tool rotational speed of $710 \mathrm{rpm}$, welding speed of $31.5 \mathrm{~mm} / \mathrm{min}$, and tilt angle of $0.5^{\circ}$ is found to be the optimum combination. In the present scenario we have 3 cutting parameter which are varied up to 3 levels. Hence $3{ }^{3}$ numbers of combinations are possible. But only 9 combinations we have taken into consideration. Therefore, there is a possibility that 
the optimum condition may lie in rest of the combinations. So to find out the optimum combination the concept average closeness coefficient value is calculated

After constructing the average closeness coefficient value select the maximum tool rotational speed, welding speed and tool tilt angle. The optimum combination based on the average values is first level of Tool rotational speed, third level of Welding speed and second level of Tool tilt angle. The optimum process parameters are tool rotational speed of $710 \mathrm{rpm}$, welding speed of $50 \mathrm{~mm} / \mathrm{min}$ and tool tilt angle of $1^{\circ}$.

Table 8 Average Closeness Coefficient Values

\begin{tabular}{|c|c|c|c|}
\hline & $\begin{array}{c}\text { TOOL ROTATIONAL } \\
\text { SPEED }\end{array}$ & $\begin{array}{c}\text { WELDING } \\
\text { SPEED }\end{array}$ & $\begin{array}{c}\text { TILT } \\
\text { ANGLE }\end{array}$ \\
\hline LEVEL 1 & $\mathbf{0 . 7 6 1 5 2 6}$ & 0.74423 & 0.74456 \\
\hline LEVEL 2 & 0.753444 & 0.746486 & $\mathbf{0 . 7 5 2 8 9}$ \\
\hline LEVEL 3 & 0.751118 & $\mathbf{0 . 7 5 6 0 2 4}$ & 0.74928 \\
\hline
\end{tabular}

Performance index value of the optimum combination is predicted by using below formula.

$$
P^{+}=A_{1}+B_{3}+C_{2}-2 T
$$

Here

$\mathrm{A}_{1=}$ level 1 of Tool rotational speed

$\mathrm{B}_{3}=$ Level 3 of Welding speed

$\mathrm{C}_{2}=$ Level 2 of tool tilt angle.

$\mathrm{T}=$ overall mean

Performance index for optimum combination of tool rotational speed of $710 \mathrm{rpm}$, welding speed of 50 $\mathrm{mm} / \mathrm{min}$ and tool tilt angle of 1 is calculated as below.

Predicted performance index $=$

$0.761526+0.756024+0.75289-2 * 0.75107$

$=0.768306$
Predicted performance index value for optimum process parameter is high compared to the $\mathrm{P}^{+}$values in table no 7 . From this it is concluded that optimum process parameters gives best results.

Simple linear regression equations are formed to each response to predict the responses of optimum level process parameters. The predicted responses are tabulated below

Table 9: Predicted Responses Values for Optimum Level

\begin{tabular}{|l|l|l|l|l|l|l|}
\hline $\begin{array}{l}\text { Tool } \\
\text { rotational } \\
\text { speed }(\mathbf{r p m})\end{array}$ & $\begin{array}{l}\text { Welding } \\
\text { speed } \\
(\mathbf{m m} / \mathbf{m i n})\end{array}$ & $\begin{array}{l}\text { Tool tilt } \\
\text { angle } \\
(\mathbf{o})\end{array}$ & $\begin{array}{l}\text { Peak } \\
\text { Load } \\
(\mathbf{K N})\end{array}$ & $\begin{array}{l}\text { Elongation } \\
\text { percentage }\end{array}$ & $\begin{array}{l}\text { Shear } \\
\text { strength } \\
\left(\mathbf{N} / \mathbf{m m}^{\mathbf{2}}\right)\end{array}$ & $\begin{array}{l}\text { Hardness } \\
\text { VH0.5 }\end{array}$ \\
\hline 710 & 50 & 1.0 & 17.64 & 5.42 & 86.08 & 72.36 \\
\hline
\end{tabular}

\section{CONCLUSION}

In this work three different parameters and three levels are considered. FSLW of AA5083AA6082 was conducted. Mechanical properties of joints were evaluated and optimum process parameters were analyzed using Deng's similarity based method. The following conclusions were drawn.

> Hardness values of AA5083 and AA6082 show a lower value at the weld than the parent metal.

$>$ The Tool rotational speed increase effectively shear strength, elongation load at peak are decreases. The reason behind this is at higher rotational speeds large amount of material flow that causes several defects on the joint.

$>$ The optimum process parameters combination such as tool rotational speed of $700 \mathrm{rpm}$, welding speed of $50 \mathrm{~mm} / \mathrm{min}$ and tool tilt angle of 1 degree yield higher performance index value
$>$ Response values for the optimum level are predicted using regression equations.

ACKNOWLEDGEMENT

Authors are greatfull to SVU College of engineering, Mechanical engineering, Tirupathi, for providing necessary equipments for conducting the experiments and mechanical tests.

\section{REFERENCES}

[1]. Mandeep Singh Sidhu1, Sukhpal Singh Chatha "Friction Stir Welding - Process and its Variables: A Review" IJETAE Volume 2, Issue 12, December 2012)

[2]. HemaPothur, Gangadhar S M, Ravindranth $\mathrm{K}$ (Jul 2012) "influence of friction stir welding parameters on the micro structural and mechanical properties of aluminum alloy 6061", International Journal of 
Applied Engineering Research, Vol 7,I ssue 8 (2012), pp 907-916

[3]. Shaikh Mohammed Shakil Prof. Yagnesh B Chauhan "Optimization of Friction Stir Welding Process Parameters for Welding Aluminum Alloys" IJSTE - International Journal of Science Technology \& Engineering | Volume 2 | Issue 02 | August 2015

[4]. Chang-Yong Lee $Æ$ Won-Bae Lee JongWoong Kim "Lap joint properties of FSWed dissimilar formed $5052 \mathrm{Al}$ and 6061 Al alloys with different thickness" J Mater Sci (2008) 43:3296-3304 DOI 10.1007/s10853-008-2525-1

[5]. Mr. Renjith CR1Mr. Rathish Raghupathy2Mr. Dhanesh GM3 "Optimization of Process Parameters for Friction Stir Lap Welding of AA6061-T6 and AA7075-T6 Aluminum Alloys Using Taguchi Technique" International Journal for Research in Technological Studies| Vol. 3, Issue 4, March 2016 | ISSN (online): 2348-1439

[6]. S. Babu, G.D. Janaki Ram, P.V. Venkatakrishnan, G. Madhusudhan Reddyand K. Prasad Rao" Microstructure and Mechanical Properties of Friction Stir LapWelded Aluminum Alloy AA2014” J. Mater. Sci. Technol., 2012, 28(5), 414-426.

[7]. Joseph Achebo1*, William Ejenavi Odinikuku2 "Optimization of Gas Metal Arc Welding Process Parameters Using Standard Deviation (SDV) and MultiObjective Optimization on the Basis of Ratio Analysis (MOORA)" Journal of Minerals and Materials Characterization and Engineering, 2015, 3, 298-308

[8]. Mohamed F. El-Santawy1,* and A. N. Ahmed2 "A SDV-MOORA Technique for Solving Multi-Criteria Decision Making Problems with No Preference" Life Science Journal 2012;9

[9]. P. Hema, M. Reddeiah, K. Ravindranath"Effect Of Pin Geometry On Friction Stir Welded Joints" paper presented at National conference on Latest Innovations in Mechanical Engineering (LIME -2013) at Andhra University College of Engineering Vishakapatnam on 28th April 2013.

[10]. P. Hema, D. Kanakaraja, K. Ravindranath “ Comparative Studyon Different Pin Geometries Of Tool Profile In Friction Stir Welding Using Artificial Neural Networks", International Journal of Mechanical Engineering And Technology (Ijmet), Issn 0976 - 6340 (Print), Issn 0976 - 6359
(Online) Volume 4, Issue 2, March - April (2013), Pp. 245-253.

[11]. HemaPothur, Gangadhar S M, Ravindranth K (Jul 2012)"Influence Of Friction Stir Welding Parameters On The Micro Structural And Mechanical Properties Of Aluminum Alloy 6061”, International Journal Of Applied Engineering Research, Vol 7, Issue 8 (2012), Pp 907-916. 